\title{
The Doctors Are In
}

Unprecedented scientific, medical, technological and even financial resources are available for human health in many parts of the world. Yet, we entered the new millennium with an unprecedented 30 -fold gap between those who live and die marginalized from health services and opportunities for a dignified life, and those who count on health as their birthright. In this context, health equity looms among the biggest challenges facing twentyfirst century societies.

The seminal 2004 study by the Joint Learning Initiative, followed by the 2006 World Health Report and more recently by the Global Health Workforce Alliance's Scaling Up, Saving Lives point to human resources as key to solving this global crisis: getting enough of the right people in the right place doing the right things at the right time. Such champions of health equity allude to the kind of physician needed within a broader strategy to train and retain a global health workforce capable of guaranteeing basic health care to everyone. They are joined by value-driven medical education reformers who advocate return to a more service-oriented ethic for medicine. Together, the two streams are producing a powerful current, as socially responsive medical education joins the broader drive for socially equitable health policy.

Yet, there is much work to be done to muster the political will needed to change the course of an entire profession and medical training with it. It is no wonder that health equity proponents often fail to consider doctors among the priority personnel needed to address the 4.3-million shortfall of health workers. Confronted with the current state of the profession in many countries, they argue that doctors are too costly, too little and too late: costs of medical education and salaries are rising; it is years before medical students give back to society; and physicians are high-end professionals, not the ones needed on the front lines. What's more, it is reasoned, medical societies are often part of the problem, not its solution. The value-driven medical education reformers, on the other hand, occasionally need to be reminded of the urgency of change, and - as Charles Boelen suggests in these pages - that curriculum reform is not enough.

Breakthroughs are happening: witness the articles in this issue of MEDICC Review reflecting the work of nine medical schools and programs that are pioneers in transforming medical education around the world. From Northern Canada, New Mexico, Cuba and Venezuela to the Philippines, Australia and South Africa, these initiatives are developing in vastly different social, political and resource environments. Yet, based on the goals they share, their paths have converged to an astounding degree-their experience suggesting that doctors need not be too costly, too few, too late or too far behind the front lines after all. In summary, as you will see in the following pages, each school or program:

1. Was founded to scale up training to meet the health needs of a specific population; and pursues measureable impact on health outcomes by their school and graduates.

2. Engages in broad enrollment of students from disadvantaged communities and provides them required support.
3. Educates their students for public service and comprehensive primary care, from prevention through treatment and rehabilitation.

4. Involves broad stakeholders, especially within disadvantaged communities and government.

5. Adopts a curriculum relevant to individual and collective health needs, instilling social commitment, cultural sensitivity, and teamwork with other health workers and communities.

6. Projects new roles: students as self-directed learners; practitioners as physician-tutors; faculty as guides; community members as partners.

7. Trains from day one in the communities where graduates are expected to practice.

8. Relies on collaboration, and actively pursues more cooperation with like-minded programs.

To some readers, these common threads may seem simply common sense. However, the effort involved in such sweeping transformation is immeasurable. Along the way, these schools face similar and often daunting challenges, not the least of which is demonstrating the quality of their training to an often skeptical and biased medical profession on the one hand, and on the other, demonstrating their relevance and positive contribution to the lives of people in need.

\section{We are speaking of more than the creation of a series of individuals. We are speaking of the education of those who care for our future. Robert F. Woollard, MD, CCFP, FCFP}

Generating a common framework and evaluation tools to measure their performance has led several of these programs to establish the Training for Health Equity Network (THEnet), whose coordinators - Dr André-Jacques Neusy and Bjorg Palsdottir - have agreed to serve as Guest Editors for this issue of the journal. Representatives of these schools will also join medical educators from around the globe in Havana this December at a promising international conference - Medical Education for the 21st Century: Teaching for Health Equity - to which MEDICC has lent its endorsement and support.

December, too, brings World AIDS Day, refocusing global attention on the need for comprehensive strategies based on strengthened health systems. In this issue, we publish a review and update of the Cuban HIVIAIDS program (Cuba's HIVIAIDS Program: Controversy, Care and Cultural Shift).

Finally, we would like to notify you of a decision in keeping with the theme of this issue and of science in the public interest: we are pleased to announce that MEDICC Review online is now an Open Access publication. The journal is freely available on the Internet, and we invite you to visit the site and share its contents: www.medicc.org/mediccreview. -1 -

\section{The Editors}

